Article

\title{
Undiagnosed diabetes mellitus and related factors in East Gojjam (NW Ethiopia) in 2016: a community-based study
}

\author{
Amsalu Taye Wondemagegn, ${ }^{1}$ Habtamu Mellie Bizuayehu, ${ }^{2}$ Dagninet Derebe Abie, ${ }^{3}$ \\ Getachew Mengistu Ayalneh, ${ }^{4}$ Tenaw Yimer Tiruye, ${ }^{2}$ Mequanint Taddele Tessema ${ }^{2}$ \\ ${ }^{1}$ Department of Biomedical Science, School of Medicine, Debre Markos University; ${ }^{2}$ Department of \\ Public Health, College of Health Sciences, Debre Markos University; ${ }^{3}$ Department of Pharmacy, \\ College of Medicine and Health Sciences, Bahir Dar University; ${ }^{4}$ Department of Medical \\ Laboratory, College of Health Sciences, Debre Markos University, Ethiopia
}

Significance for public health

Currently, diabetes is the second most common non-communicable disease in Ethiopia. Its burden is $4.8 \%$ in this country, though three quarter of its population live with undiagnosed diabetes mellitus (DM), which could lead to several complications such as heart failure, blood vessels, eyes, kidneys, and nerves damages. Evidence shows that the disease is increasing through time. Early detection of DM is vital for a timely intervention to prevent lifethreatening complications. Efforts should be made by politicians, decision makers and other healthy institutions to implement screening modality and early interventions.

\section{Abstract}

Introduction. Currently, diabetes is the second most common non-communicable disease (NCD) in Ethiopia. Its burden is $4.8 \%$ in this country, even though three quarter of its population live with undiagnosed diabetes mellitus (DM), which causes complications like heart failure, blood vessels, eyes, kidneys and nerves damages. Early detection of DM is vital for a timely intervention to prevent these life threatening complications. The aim of this study was to assess the prevalence of undiagnosed DM and related factors in East Gojjam, North West Ethiopia, in 2016.

Materials and methods. A community-based cross-sectional study was conducted among 757 individuals in East Gojjam from June to September 2016. The sampled population was selected using multi-stage cluster sampling method. Basic data were collected in Amharic (local language) and a pretested interviewer administered the questionnaire. Peripheral blood samples were collected by puncturing the ring finger in order to measure fasting blood glucose. Univarite and multivariate logistic regressions analysis were performed using Statistical Package for Social Sciences (SPSS) software version 20.0.

Results. The percentage of undiagnosed DM in the study area was $11.5 \%(95 \% \mathrm{CI}=9.2,13.7)$. The prevalence was $11.3 \%$ among male vs. $11.8 \%$ among female; $13.4 \%$ in urban areas $v s .10 .3 \%$ in rural areas. The occurrence of undiagnosed DM was mainly associated with older age $(\mathrm{AOR}=5.99,95 \% \mathrm{CI}=1.54,23.24)$, family history of diabetes $(\mathrm{AOR}=9.86,95 \% \mathrm{CI}=4.25,22.89)$, history of gestational diabetes $(\mathrm{AOR}=3.01,95 \% \mathrm{CI}=1.17,8.39)$ and sedentary behaviour $>4$ hours per day $(\mathrm{AOR}=2.13,95 \% \mathrm{CI}=1.04,4.34)$. Being non-smoker $(\mathrm{AOR}=0.05,95 \% \mathrm{CI}=0.01,0.17)$ and unmarried $(\mathrm{AOR}=0.09,95 \% \mathrm{CI}=0.02,0.42)$ were also predictive characteristics for undiagnosed DM in the study area.
Conclusions. In conclusion, this study revealed a relatively high prevalence of undiagnosed DM in the study area. The occurrence of undiagnosed DM was significantly higher when associated with the age of the participants, their marital status, history of hypertension, diabetes family history, history of gestational diabetes mellitus, current smoking practices and sedentary behaviour. Thus, efforts have to be made, particularly by the individuals involved in health practice, to early detect the disease and thereby initiate a suitable therapeutic service, before complications arise

\section{Introduction}

Diabetes is a chronic metabolic disease characterised by longlasting hyperglycaemia, that occurs either when the pancreas does not produce enough insulin or when the body cannot effectively use the insulin it produces. Insulin is a hormone secreted by the pancreas that regulates blood sugar. When the body can't produce enough insulin or can't use the insulin it makes, it results in high blood sugar values that lead to frequent urination, increased thirst and hunger. ${ }^{1,2}$ The International Diabetes Federation (IDF) estimates that about 387 million (8.3\%) people lived with diabetes in 2014 and the number of individuals is expected to rise by $53 \%$ in 2035, which means 592 million cases. ${ }^{3,4}$

Diabetes is the $4^{\text {th }}$ cause of death globally. The overall risk of dying among people with diabetes at young age is double compared with those without diabetes. ${ }^{3}$ Every 7 seconds, one person dies because of diabetes-related cause. The overall diabetes-related death was 4.9 million per year worldwide. ${ }^{4,5}$ About eight every ten people with diabetes (77\%) live in low- and middle-income countries.

In Africa, this disease affected 21.5 million (5.1\%) people in 2014 and is expected to raise to 41.5 million in 2035, with an increase of $93 \%$. Hence, the current $5.1 \%$ would rise to $5.3 \%$ in 2035. The total diabetes related death was 480,900 per year in the region. Three quarter cases $(75.1 \%)$ were dying $<60$ y.o., which is highest percentage of deaths under the age of 60 globally. ${ }^{4,5}$

Ethiopia is one of the countries mostly affected by the disease. According to the 2014 report of IDF, the number of adults aged 20-79 years, living with diabetes in the country was 2.135 million $(4.8 \%)$. The total diabetes related death was 34,262 in the country. ${ }^{4,5}$

In North West Ethiopia, Gondar, the prevalence of the disease was $2.1 \%$ in rural areas and $5.1 \%$ in urban areas. ${ }^{6}$ Similarly, the prevalence of the disease was $8 \%$ and $0.5 \%$ in Southern and 
southwest Ethiopia respectively. ${ }^{7,8}$ In central Ethiopia, Addis Ababa, the percentage of the disease was $6.5 \%$ among Commercial Bank employees. ${ }^{9}$ The disease was accounting $20 \%$ of the cases among patients admitted in Hospitals located in Addis Ababa, Ethiopia, which is the second most common non-communicable disease (NCD) ${ }^{10}$ To cure the disease about 612.2 billion US dollars were used in 2014 , which represent $11 \%$ of worldwide healthcare expenditure. This healthcare expenditure is expected to rise by 627.3 billion in 2035 . Africa allocates the lowest diabetes-related expenditure, $1 \%$ of worldwide total. About US \$ 4.5 billion healthcare expenditure was used in 2014 and this cost is expected to rise to 6.4 billion in 2035. Ethiopia is allocating about US \$ 32.7 per person. ${ }^{4,5}$

The complications of DM become very severe in absence of an early diagnosis. In case of severe complications, $50 \%$ of patients don't know having DM. In 2014 about 179.2 million people worldwide lived with undiagnosed DM. ${ }^{3}$

Africa region has highest percentage of undiagnosed people compared to other regions. About $62.3 \%$ of persons with the diseases do not know being affected by DM and about 13.4 million people were recorded to have undiagnosed DM in 2014.4,5 Similarly, Ethiopia has three quarter persons $(75.1 \%)$ with DM, who do not know having it; which is about $1,603,100$ people in 2014., ${ }^{4,5}$ In Gondar, north west Ethiopia, about 69\% individuals live with undiagnosed DM. ${ }^{6}$ As far as we know, no prior study has been conducted in the current study area. Moreover, the level of knowledge is essential to decide whether the problem is significant or not and to give proper attention before complications occur. Therefore, the present study was mainly aimed at determining the level of undiagnosed DM and to identify factors related to its occurrence.

\section{Materials and Methods}

\section{Study design and setting}

A cross-sectional study with a community-based approach was conducted by using quantitative research methods. The study was done from June 1 to September 30, 2016 in East Gojjam zone, which is one the local administration of Amhara regional State in eastern Ethiopia. All permanent residents in the East Gojjam zone (living in the area for at least 6 months) and aged $\geq 25$ y.o were enrolled as source group. The primary, secondary and tertiary sampling units were districts, Kebeles (administrative unit below district) and villages respectively.

\section{Sampling and data collection strategy}

The sample size was calculated based on the assumption of $95 \%$ confidence interval, $5 \%$ margin of error, design effect 2 and using the undiagnosed DM proportion which is $69 \%$ from previous study. ${ }^{6}$ The required sample size calculated using Open-Epi Version 2.3 was 658 and the final sample size after adding $15 \%$ contingency is becoming 756.7 757. To get study participants multistage cluster sampling technique was used. Firstly, from zone $30 \%$ of districts i.e. Machakel, Bibugn, Amber, Dejen, Enbsie sar mdr, Hulet eju nesie was selected by lottery method and then 1 Kebele was selected randomly from the selected districts. Lastly, one village was selected randomly from selected Kebeles. Sample frame was prepared by conducting census in selected villages and selection of participants was done using systematic sampling method.

Data collection tool for interview was developed by reviewing different literatures. The questionnaire was translated into local language and back translated in English to maintain consistency. Background data were collected trough an interviewer-administered questionnaire. For laboratory data, fasting blood glucose was measured as per the WHO recommendations..$^{11}$ Early in the morning before participants took their breakfast, peripheral blood samples on the ring finger was punctured and collected. Plasma glucose levels was then measured using the glucose oxidase- 6 phosphate dehydrogenase method. ${ }^{12}$ Participants were classified as having DM if they had fasting glucose levels $>126 \mathrm{mg} / \mathrm{dL}$, which was confirmed by repeating the test on am different day. ${ }^{11}$ For data collection and daily supervision, laboratory professionals were recruited from West Gojjam (a different zone) in order not to recognize the respondents and minimize social desirability bias. They were trained by a principal investigator about the objective of the study, confidentiality of information, blood sample taking and testing and about the contents of the questionnaire in detail. The outcome variable of study was undiagnosed DM and the independent variables were: socio-demographic and economic characteristics like age, sex, weight, height, residence, marital status, religion, educational level, income; behavioural characteristics like smoking, alcohol drinking, eating of vegetables and fruits, physical activity status, sedentary behaviour; history of hypertension, history of gestational diabetes, family history of DM and others.

\section{Operational definition}

Physical activity commonly refers to physical movement that will improves health. Physical activity data were collected using Global Physical Activity Questionnaire (GPAQ) and activity levels were calculated by using the cut-off points in the analysis guide. ${ }^{13}$ Accordingly, the subjects were categorized as having low physical activity [metabolic equivalent units (MET) $<600 /$ week], moderate physical activity [MET in between 600-1200] and high physical activity level [MET above 1200].

On the other hand, sedentary behaviour was measured by asking about the time spent sitting (computer use, working, watching television, reading) during a typical week. ${ }^{13}$ Lastly, responses were dichotomized as $<4$ hours/day and $\geq 4$ hours/day.

Body mass index (BMI), which is a measure that relates body weight to height, was also recorded.

\section{Statistical analysis}

Each questionnaire were coded and entered in to Epi Info version 3.5 statistical package and were exported to SPSS 20.0 statistical package for analysis of statistical inferences. Data cleaning and editing were made before analysis. The result of study is presented in both descriptive statistics $(\%$, table, graph, mean, median values, dispersion measurements like standard deviation, interquartile range) and inferential statistics (odds ratio). Before running the multiple logistic regressions assumption of multi-colinearity was checked using the tolerance/variance inflation factor. Binary logistic regressions was used to calculate the univariate and multivariate adjusted odds ratio and to determine independent predictors of dependent variable.

In multivariate logistic regressions model, we entered only those variables that were associated with dependent variable with $\mathrm{P}$-value $\leq 0.2$ in univariate analysis, biologically important and not collinear. The cut off point for significant association was $\mathrm{P}<0.05$.

The study proposal was approved by Debre Markos university ethical review committee. Permission to conduct study was also obtained from the concerned bodies of East Gojjam zone, districts, Kebeles and villages. To protect confidentiality no personal identifier was recorded in the questionnaire and the recorded data was not accessed by a third person. Verbal informed consent was 
obtained from participants. Participants were informed as they had a full right to quit to participate in the study at any time of collection procedures. Study participants who identified as having DM were referred to the nearby health institutions for further treatment and follow-up.

\section{Results}

Out of 757 total planned study participants, 722 participated in the study making the overall response rate of the study $95.4 \%$. In this study, $439(60.8 \%)$ of the respondents were living in rural area. Among the total study participants about $426(59 \%)$ were male and 296 (41\%) were female, which makes sex ratio 1.44 . The mean age of the study participants was 49 years \pm 16.29 SD and about 213 $(29.5 \%)$ of the study participants fell in the age group between 35 to 44 years. Out of the total study participants, $475(65.8 \%)$ were currently married, 277 (38.4\%) were illiterate, 119 (16.5\%) had certificate and above education level, 389 (56.1\%) had monthly household income of less than 1750 ETB and 79 (10.9\%) had body mass index of greater or equal to 25 (Table 1).

The present study found that about $8.3 \%$ of patients had a previous history of hypertension, $23.7 \%$ had a history of diabetes mellitus among $1^{\text {st }}$ degree relatives (brothers, sisters, mothers or fathers), $8.1 \%$ had a history of gestational diabetes and $21.4 \%$ had a baby with birth weight $\geq 4 \mathrm{~kg}$. In addition, $18.3 \%$ had current

Table 1. Socio-demographic and economic characteristics of the study participants by diabetic status, Northwest Ethiopia, 2016.

\begin{tabular}{|c|c|c|c|}
\hline $\begin{array}{l}\text { Variables and coding } \\
\text { categories }\end{array}$ & $\begin{array}{l}\text { Undiagnosed } \\
\text { diabetic } \\
\text { case, n (\%) }\end{array}$ & $\begin{array}{l}\text { Non-diabetic } \\
\text { case, } \\
\text { n }(\%)\end{array}$ & $\begin{array}{l}\text { Total, } \\
\text { n (\%) }\end{array}$ \\
\hline $\begin{array}{l}\text { Area of residence } \\
\text { Urban } \\
\text { Rural }\end{array}$ & $\begin{array}{l}38(13.4) \\
45(10.3)\end{array}$ & $\begin{array}{l}245(86.6) \\
394(89.7)\end{array}$ & $\begin{array}{l}283(39.2) \\
439(60.8)\end{array}$ \\
\hline $\begin{array}{l}\text { Sex of participants } \\
\quad \text { Male } \\
\text { Female } \\
\end{array}$ & $\begin{array}{l}48(11.3) \\
35(11.8)\end{array}$ & $\begin{array}{l}378(88.7) \\
261(88.2)\end{array}$ & $\begin{array}{l}426(59.0) \\
296(41.0)\end{array}$ \\
\hline $\begin{array}{l}\text { Age group of participants } \\
\qquad \begin{array}{l}25-34 \\
35-44 \\
45-54 \\
55-64 \\
\geq 65\end{array}\end{array}$ & $\begin{array}{l}5(3.9) \\
25(11.7) \\
19(17.1) \\
17(16.7) \\
17(10.1)\end{array}$ & $\begin{array}{c}122(96.1) \\
188(88.3) \\
92(82.9) \\
85(83.3) \\
152(89.9)\end{array}$ & $\begin{array}{l}127(17.6) \\
213(29.5) \\
111(15.4) \\
102(14.1) \\
169(23.4)\end{array}$ \\
\hline $\begin{array}{l}\text { Marital status } \\
\text { Currently married } \\
\text { Never married } \\
\text { Divorced } \\
\text { Widowed }\end{array}$ & $\begin{array}{c}63(13.3) \\
4(3.3) \\
6(13.0) \\
10(12.7)\end{array}$ & $\begin{array}{l}412(86.7) \\
118(96.7) \\
40(87.0) \\
69(87.3)\end{array}$ & $\begin{array}{c}475(65.8) \\
122(16.9) \\
46(6.4) \\
79(10.9)\end{array}$ \\
\hline $\begin{array}{l}\text { Education level } \\
\text { No formal education } \\
\text { Primary education (grad } \\
\text { Secondary education (g } \\
90 \text { (12.5) } \\
\text { Certificate and above }\end{array}$ & $\begin{array}{l}30(10.8) \\
1-8) 23(9.7) \\
10-12) \\
20(16.8)\end{array}$ & $\begin{array}{c}247(89.2) \\
213(90.3) \\
10(11.1) \\
99(83.2)\end{array}$ & $\begin{array}{c}277(38.4) \\
236(32.7) \\
80(88.9) \\
119(16.5)\end{array}$ \\
\hline $\begin{array}{l}\text { Monthly household income }( \\
\quad<1750 \\
\quad \geq 1750\end{array}$ & $\begin{array}{l}\text { TB) } \\
\begin{array}{l}43(11.1) \\
38(12.5)\end{array}\end{array}$ & $\begin{array}{l}346(88.9) \\
267(87.5)\end{array}$ & $\begin{array}{l}389(56.1) \\
305(43.9)\end{array}$ \\
\hline $\begin{array}{l}\text { Body mass index }\left(\mathrm{kg} / \mathrm{m}^{2}\right) \\
\quad<18 \\
\quad 18-24.99 \\
\geq 25\end{array}$ & $\begin{array}{l}6(14.6) \\
66(11.0) \\
11(13.9)\end{array}$ & $\begin{array}{c}35(85.4) \\
536(89.0) \\
68(86.1)\end{array}$ & $\begin{array}{c}41(5.7) \\
602(83.4) \\
79(10.9)\end{array}$ \\
\hline
\end{tabular}

smoking practices, $62.3 \%$ had current alcohol drinking practices, $29.2 \%$ had less than 3 times per week eating practices of fruits and vegetables, $22.6 \%$ had low intensity physical activity level and about $27 \%$ had sedentary behaviour for more than 4 hours per day (Table 2).

\section{Proportion of undiagnosed diabetes mellitus}

The present study found that the overall magnitude of undiagnosed diabetes mellitus in the study area was $11.5 \%(95 \% \mathrm{CI}=9.2$, 13.7). The prevalence was $11.3 \%(95 \% \mathrm{CI}=8.2,14.1)$ among male study participants and $11.8 \%(95 \% \mathrm{CI}=8.1,15.5)$ among female participants. The prevalence of undiagnosed diabetes mellitus in urban area was $13.4 \%$ while in rural area was about $10.3 \%$. The study revealed that, there were no statistically significant difference in terms of diabetic status by sex and residence.

The highest proportion of undiagnosed diabetes mellitus was observed within the group of study participants aged 35-44 years and married. This study showed that the prevalence of undiagnosed diabetes mellitus was relatively high with the increasing of age of participants. In addition, the prevalence of undiagnosed DM in the zone, as stratified by districts and sex can be seen in Figure 1. There were no identified cases of undiagnosed diabetes mellitus in Machakel district.

\section{Factors associated with undiagnosed diabetes mellitus}

Multivariate logistic regression analysis of factors associated

Table 2. Medical history and healthy practices of study participants by diabetic status, Northwest Ethiopia, 2016.

$\begin{array}{cccc}\begin{array}{l}\text { Variables and coding } \\ \text { categories }\end{array} & \begin{array}{c}\text { Undiagnosed } \\ \text { diabetic }\end{array} & \begin{array}{c}\text { Non-diabetic } \\ \text { case, n (\%) }\end{array} & \text { Total, } \\ & \text { n (\%) } & \end{array}$

History of hypertension

$\begin{array}{lccc}\text { Yes } & 32(53.3) & 28(46.7) & 60(8.3) \\ \text { No } & 51(7.7) & 611(92.3) & 662(91.7) \\ \text { betes family history } & & & \\ \text { Yes } & 39(23.1) & 130(76.9) & 169(23.7) \\ \text { No } & 44(8.1) & 501(91.9) & 545(76.3)\end{array}$

History of gestational diabetes

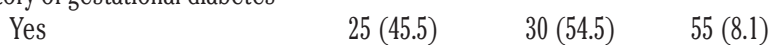

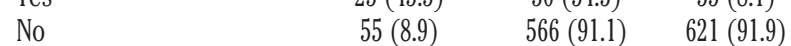

$\begin{array}{cccc}\text { History of having baby weighing }>4 \mathrm{~kg} \text { at birth } & & \\ \text { Yes } & 15(10.6) & 127(89.4) & 142(21.4)\end{array}$

\begin{tabular}{llll} 
No & $64(12.3)$ & $457(87.7)$ & $521(78.6)$ \\
\hline
\end{tabular}

Current smoking

\begin{tabular}{lccc} 
Yes & $5(3.8)$ & $126(96.2)$ & $131(18.3)$ \\
No & $78(13.4)$ & $505(86.6)$ & $583(81.7)$ \\
Current alcohol drinking & & & \\
Yes & $42(9.4)$ & $403(90.6)$ & $445(62.3)$ \\
No & $41(15.2)$ & $228(84.8)$ & $269(37.7)$ \\
\hline
\end{tabular}

Frequency of eating fruits and vegetables

\begin{tabular}{lccc}
$<3$ times per week & $21(10.1)$ & $187(89.9)$ & $208(29.2)$ \\
$3-4$ times per week & $40(11.3)$ & $313(88.7)$ & $353(49.6)$ \\
$>4$ times per week & $22(14.6)$ & $129(85.4)$ & $151(21.2)$ \\
ysical activity level in a typical week & & \\
Low (<600 MET value) & $23(14.1)$ & $140(85.9)$ & $163(22.6)$ \\
Moderate (600-1200 MET value) $)$ & $13(14.6)$ & $76(85.4)$ & $89(12.3)$ \\
High (>1200 MET value) & $47(10.0)$ & $423(90.0)$ & $470(65.1)$ \\
\hline & & & \\
dentary behaviour & $48(9.2)$ & $475(90.8)$ & $523(73.0)$ \\
$<240$ minutes per day & $34(17.6)$ & $159(82.4)$ & $193(27.0)$ \\
\hline$=240$ minutes per day & & &
\end{tabular}


with undiagnosed diabetes mellitus found that the age of the participants, their marital status, history of hypertension, diabetes family history, history of gestational DM, current smoking practices and sedentary behaviour were the main factors that revealed statistical significant association with undiagnosed diabetes mellitus. The odds ratio of undiagnosed DM was about 4 times higher $(\mathrm{AOR}=3.62,95 \% \mathrm{CI}=1.12,12.09)$ in those study participants aged $35-44$ years, about 6 times higher $(\mathrm{AOR}=5.99,95 \% \mathrm{CI}=1.54$, 23.24) in those study participants aged $45-54$ years, compared to those aged 25-34 years. The occurrence of undiagnosed DM among single study participants were about $91 \%$ less likely $(\mathrm{AOR}=0.09,95 \% \mathrm{CI}=0.02,0.42)$ compared to those currently in union study participants. In this study, the odds of undiagnosed diabetes mellitus were about 4.5 times higher ( $\mathrm{AOR}=4.5$, $95 \% \mathrm{CI}=1.74,11.63$ ) among those study participants having previous history of hypertension compared to those without previous history of hypertension. The odds of undiagnosed diabetes mellitus were about 10 times higher $(\mathrm{AOR}=9.86,95 \% \mathrm{CI}=4.25,22.89)$ among those participants with history of diabetes among $1^{\text {st }}$ degree relatives compared to those without the family history of diabetes (Table 3).

The study also found that the occurrence of undiagnosed DM was about 3 times higher $(\mathrm{AOR}=3.01,95 \% \mathrm{CI}=1.17,8.39)$ among those with a history of gestational diabetes. The occurrence of undiagnosed DM was about $95 \%$ less likely ( $\mathrm{AOR}=0.05$, $95 \% \mathrm{CI}=0.01,0.17$ ) among those studied population without current smoking practices compared to those with the practices. Moreover, the odds of undiagnosed DM were about 2 times higher $(\mathrm{AOR}=2.13,95 \% \mathrm{CI}=1.04,4.34)$ among those participants with sedentary behaviour (more than 4 hours per day) compared to those having sedentary behaviour of less than 4 hours per day. Lastly, the current study found that sex, body mass index, alcohol drinking practices, socioeconomic factors like educational status, income, and healthy behaviours like physical activity, eating fruits and vegetables, didn't reveal a statistically significant association with undiagnosed DM (Table 3).

\section{Discussions}

The present study found that the percentage of people living with undiagnosed DM in our study area is $11.5 \%$. The results obtained were comparable to those of Zhou et al. ${ }^{14}$ On the other hand, we have found a relatively higher proportion of undiagnosed DM compared to the results of a previous local study. ${ }^{15}$ This might

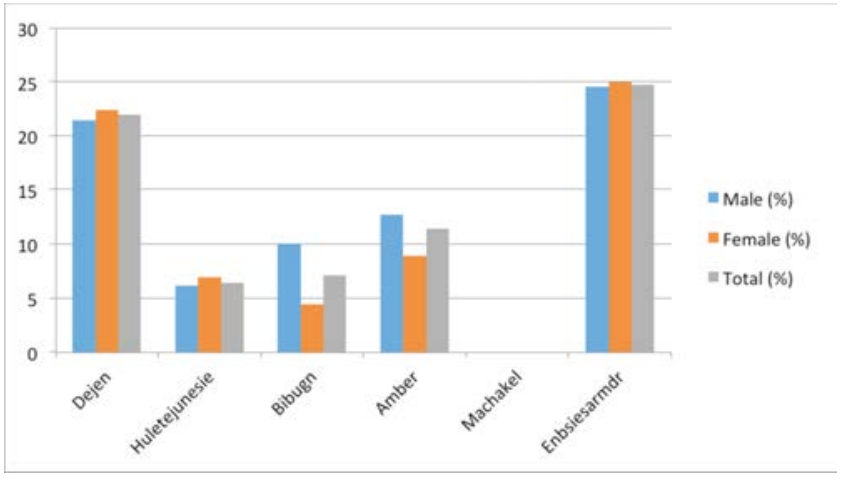

Figure 1. Prevalence of undiagnosed diabetes mellitus of the zone by districts and sex, northwest Ethiopia, 2016. be due to the geographical differences and associated lifestyle among the studied population.

The prevalence is even higher when compared to the 2012 country level, as estimated by the IDF. ${ }^{16}$ This relative higher prevalence of undiagnosed DM in this study is in line with the worldwide expected greatest increase of DM, especially in developing countries. The major incidence of diabetes in developing countries will be due to the increase of urbanization and lifestyle changes, which include increasingly sedentary behaviours, less physical activity and nutrition transition, as indicated by the higher intake of foods that are rich in calories but nutrient-poor.

Our finding showed that most cases of undiagnosed DM were more likely to be greater than 35 years old. The occurrence was significantly higher among older age group participants compared to younger age groups, which is in line with the previous local study. ${ }^{6}$ This is probably due to people's tendency to exercise less, loss muscle mass and gain weight as they get older. It is established

Table 3. Multivariate logistic regression analysis of factors associated with undiagnosed diabetes among residents of East Gojjam, northwest Ethiopia, 2016.

\begin{tabular}{|c|c|c|}
\hline Variables & Coding categories & AOR $(95 \% \mathrm{CI})$ \\
\hline Living residence & $\begin{array}{l}\text { Urban } \\
\text { Rural }\end{array}$ & $\begin{array}{c}1.18(0.55,2.53) \\
1\end{array}$ \\
\hline Sex of study participants & $\begin{array}{l}\text { Male } \\
\text { Female }\end{array}$ & $\begin{array}{c}1.43(0.72,2.81) \\
1\end{array}$ \\
\hline Age group of participants (years) & $\begin{array}{c}25-34 \\
35-44 \\
45-54 \\
55-64 \\
\geq 65\end{array}$ & $\begin{array}{c}1 \\
3.62(1.12,12.09)^{*} \\
5.99(1.54,23.24)^{*} \\
3.59(0.86,14.95) \\
3.33(0.80,13.84)\end{array}$ \\
\hline Marital status & $\begin{array}{l}\text { Currently married } \\
\text { Never married } \\
\text { Divorced } \\
\text { Widowed }\end{array}$ & $\begin{array}{c}1 \\
0.09(0.02, .42)^{* *} \\
0.84(0.26,2.76) \\
0.90(0.33,2.48)\end{array}$ \\
\hline Education status & $\begin{array}{l}\text { No formal education } \\
\text { Primary education } \\
\text { Secondary education } \\
\text { Certificate and above }\end{array}$ & $\begin{array}{c}1 \\
0.84(0.34,2.06) \\
1.33(0.43,4.17) \\
1.39(0.42,4.61)\end{array}$ \\
\hline Monthly household income (ETB) & $\begin{array}{l}<1750 \\
\geq 1750\end{array}$ & $\begin{array}{c}1 \\
1.03(0.55,1.91)\end{array}$ \\
\hline Body mass index $\left(\mathrm{kg} / \mathrm{m}^{2}\right)$ & $\begin{array}{l}<18 \\
18-24 \\
\geq 25\end{array}$ & $\begin{array}{c}1.58(0.56,5.02) \\
1 \\
1.32(0.51,3.42)\end{array}$ \\
\hline History of hypertension & $\begin{array}{l}\text { Yes } \\
\text { No }\end{array}$ & $\begin{array}{c}4.50(1.74,11.63)^{* *} \\
1\end{array}$ \\
\hline Diabetes family history & $\begin{array}{l}\text { Yes } \\
\text { No }\end{array}$ & $\begin{array}{c}9.86(4.25,22.89)^{* *} \\
1\end{array}$ \\
\hline History of gestational diabetes & $\begin{array}{l}\text { Yes } \\
\text { No }\end{array}$ & $\begin{array}{c}3.01(1.17,8.39)^{*} \\
1\end{array}$ \\
\hline Current smoking & $\begin{array}{l}\text { Yes } \\
\text { No }\end{array}$ & $\begin{array}{c}1 \\
0.05(0.01,0.17)^{* *}\end{array}$ \\
\hline Current alcohol drinking & $\begin{array}{l}\text { Yes } \\
\text { No }\end{array}$ & $\begin{array}{c}0.53(0.28,1.03) \\
1\end{array}$ \\
\hline Physical activity level in a typical we & $\begin{array}{c}\text { Low } \\
\text { Moderate } \\
\text { High }\end{array}$ & $\begin{array}{c}0.56(0.21,1.45) \\
1 \\
0.49(0.21,1.16)\end{array}$ \\
\hline Sedentary behaviour & $\begin{array}{l}240 \text { minutes per day } \\
240 \text { minutes per day }\end{array}$ & $\begin{array}{c}1 \\
2.13(1.04,4.34)^{*}\end{array}$ \\
\hline
\end{tabular}

*P $<0.05, * * \mathrm{P}<0.005$. 
that the more fatty tissue people have, the more resistant their cells become to insulin. Moreover, we found a higher prevalence of undiagnosed DM among married participants which is also in line with the previous study. ${ }^{17}$ This finding, however, is in contrast with another study conducted elsewhere, ${ }^{18}$ which revealed no statistically significant association between marital status and DM. Thus, further studies might be required to explore this association.

In this study, relative occurrence of undiagnosed DM was significantly higher among study participants with a history of hypertension, which is consistent with previous studies. ${ }^{15}$ This occurrence partially due to physiological traits; this means that the effects caused by each disease tend to make the other disease more likely to occur. In addition, the two diseases are more likely to occur together simply because they have important shared risk factors. We also demonstrated that study participants with sedentary beahviour were at higher risk of diabetes mellitus, which is also consistent with previous studies conducted elsewhere. ${ }^{6}$ This may be due to the fact that physical activity helps one to control his/her weight, use up glucose as energy and make once cells more sensitive to insulin. Respondents with a history of diabetes among $1^{\text {st }}$ degree relatives were at higher risk of undiagnosed diabetes mellitus, which is supported by previous studies. ${ }^{6}$ This might be attributed to the genetics of diabetes. In addition, lifestyle choices tend to run in the family. Sedentary parents tend to have sedentary children. Parents with unhealthy eating habits are likely to pass them on to the next generation. Moreover genetics play a big part in determining weight. Also, the current study found that undiagnosed diabetes were significantly higher in those participants with history of gestational diabetes. It is an established fact that individuals with gestational diabetes have an increased risk of developing diabetes mellitus in the future. Furthermore, the present study found the occurrence of undiagnosed diabetes was significantly higher among those participants with current smoking practices, which is also supported by previous studies conducted elsewhere. ${ }^{19,20}$ Several reasons have been suggested to elaborate these associations. It has been established that smoking is a possible risk factor for insulin resistance as well as worsen glucose metabolism. ${ }^{21}$ In addition it is known that smoking has been associated with a risk of chronic pancreatitis and pancreatic cancer, ${ }^{22,23}$ which intern leads to the risk of diabetes.

Finally, the present study found that socioeconomic status don't affect significantly the association with undiagnosed DM, which is consistent with a previous study conducted elsewhere. ${ }^{24}$ In contrast to these findings, another study has showed an inverse association between diabetes mellitus and socioeconomic status. ${ }^{25}$ Accordingly, developing countries are experiencing an increased risk of diabetes, compared to other countries.

The strength of this study is that we used a community-based approach based on the WHO standards to assess DM status, ${ }^{11}$ in order to enhance generalizability of our findings. However, the study might have several limitations: social desirability bias in giving the correct responses, though conditions are settled to remove/minimize this; recall bias for questions asking prior conditions of the participants; temporal relationship is not covered due to the nature of cross sectional study. In addition, it provided a chance for interviewer bias, as the study is interviewer based.

\section{Conclusions}

In conclusion, this study found a relatively high prevalence of undiagnosed diabetes in the study area. The occurrence of the undiagnosed DM was significantly higher when associated with the age of the participants, their marital status, history of hypertension, diabetes familiar history, history of gestational diabetes mellitus, current smoking practices and sedentary behaviour. Thus, to minimise the problems associated with the occurrence of DM, efforts have to be made, particularly by the individuals involved in health practice, to early detect the disease and thereby initiate a suitable therapeutic service, before complications arise. In addition, a healthy behaviour is strongly suggested (i.e. stop smoking and watching television).

Correspondence: Amsalu Taye Wondemagegn, Department of Biomedical Science, School of Medicine, Debre Markos University, 3, Debre Markos, Ethiopia.

Tel.: +25.192.1815441.

E-mail: 50amsalu@gmail.com

Key words: Diabetes mellitus; Ethiopia; east Gojjam zone; undiagnosed diabetes; prevalence; community-based study.

Acknowledgments: the authors would thank Debre Markos University for giving the chance to participate in research work by providing financial support. Moreover, we spread out our thankfulness to, east Gojjam zone administration bodies and the study populations who had participated in the study. Contributions: ATW, principal investigator, conception, design and writing of the proposal, data collection, data entry, analysis, interpretation, manuscript preparation; HMB, conception, design and writing of the proposal, data entry, analysis and manuscript preparation; DDA, GMA, TYT and MTT, manuscript review, data collection, analysis and interpretation, manuscript preparation.. Conflict of interest: the authors declare no potential conflict of interest.

Received for publication: 22 February 2017.

Accepted for publication: 31 March 2017.

(C) Copyright A.T. Wondemagegn et al., 2017

Licensee PAGEPress, Italy

Journal of Public Health Research 2017;6:834

doi:10.4081/jphr.2017.834

This work is licensed under a Creative Commons Attribution NonCommercial 4.0 License (CC BY-NC 4.0).

\section{References}

1. WHO. Definition, diagnosis and classification of diabetes mellitus and its complications. Part 1: Diagnosis and classification of diabetes mellitus. Geneva: World Health Organization; 1999.

2. Van Dam RM. The epidemiology of lifestyle and risk for type 2 diabetes. Eur J Epidemiol 2003;18:1115-25.

3. WHO. Global status report on non-communicable diseases. Geneva: World Health Organization; 2010.

4. International Diabetes Federation. IDF diabetes atlas. 6th ed. Brussels: IDF; 2013.

5. International Diabetes Federation. IDF diabetes atlas. Revision 6th ed. Brussels: IDF; 2014.

6. Abebe SM, Berhane Y, Worku A, Assefa A. Diabetes mellitus in North West Ethiopia: a community based study. BMC Public Health 2014;14:97.

7. Sachithananthan V, Loha E, Gose M. Prevalence of diabetes mellitus, hypertension and lipodystrophy in HAART receiving HIV patients in southern Ethiopia. Int STD Res Rev 2013;1:111.

8. Muluneh AT, Haileamlak A, Tessema F, et al. Population based survey of chronic non-communicable diseases at Gilgel Gibe field research center, southwest Ethiopia. Ethiop J Health Sci 2012:22. 
9. Nshisso LD, Reese A, Gelaye B, et al. Prevalence of hypertension and diabetes among Ethiopian adults. Diabetes Metab Syndr 2012;6:36-41.

10. Bekele, A Teklie H, Tadesse M, et al. Pattern and trend of medical admissions of patients of chronic non-communicable diseases in selected hospitals in Addis Ababa, Ethiopia. ASRJETS 2015;13:34-48.

11. Longo-Mbenza B, Ngoma DV, Nahimana D, et al. Screen detection and the WHO stepwise approach to the prevalence and risk factors of arterial hypertension in Kinshasa. Eur J Cardiovasc Prev Rehabil 2008:15:503-8.

12. 77 ELEKTRONIKA Kft, Senso Card Blood Glucose Test Strip. 2008, 1 (0).

13. WHO. Global physical activity questionnaire (GPAQ) analysis guide. Available from: http://www.who.int/chp/steps/resources/GPAQ_Analysis_Gui de.pdf.

14. Zhou X, Ji L, Luo Y, et al. Risk factors associated with the presence of diabetes in Chinese communities in Beijing. Diab Res Clin Pract 2009;86:233-8.

15. Megerssa YC, Gebre MW, Birru SK, et al. Prevalence of undiagnosed diabetes mellitus and its risk factors in selected institutions at Bishoftu Town, East Shoa, Ethiopia. J Diabetes Metab 2013;S12:008.

16. Murad MA, Abdulmageed SS, Iftikhar R, Khaled Sagga B. Assessment of the common risk factors associated with type 2 diabetes mellitus in Jeddah. Int J Endocrinol 2014;2014:
616145.

17. Rahmanian K, Shojaei M, Sotoodeh Jahromi A. Relation of type 2 diabetes mellitus with gender, education, and marital status in an Iranian urban population. Rep Biochem Mol Biol 2013;1:64-8.

18. Will JC, Galuska DA, Ford ES, et al. Cigarette smoking and diabetes mellitus: evidence of a positive association from a large prospective cohort study. Int J Epidemiol 2001;30:540-6.

19. Wei X, Meng E, Yu S. A meta-analysis of passive smoking and risk of developing type 2 diabetes mellitus. Diabetes Res Clin Pract 2015;107:9-14.

20. Fagard RH, Nilsson PM. Smoking and diabetes - the double health hazard. Prim Care Diabetes 2009;4:2005-9.

21. Lynch SM, Vrieling A, Lubin JH, et al. Cigarette smoking and pancreatic cancer: a pooled analysis from the pancreatic cancer cohort consortium. Am J Epidemiol 2009;170:403-13.

22. Ye X, Lu G, Huai J, Ding J. Impact of smoking on the risk of pancreatitis: a systematic review and meta-analysis. PLoS One 2015;10:e0124075.

23. Wilder RP, Majumdar SR, Klarenbach SW, Jacobs P. Socioeconomic status and undiagnosed diabetes. Diabetes Res Clin Pract 2005;70:26-30.

24. Connolly V, Unwin N, Sherriff P, et al. Diabetes prevalence and socioeconomic status: a population based study showing increased prevalence of type 2 diabetes mellitus in deprived areas. J Epidemiol Community Health 2000;54:173-7. 